\title{
The Impact Of A Secondary Market On Video Game Purchase Intentions
}

\author{
Nicole F. Velasquez, Utah State University, USA \\ Hannah Newman, Pepperdine University, USA \\ Scott Miller, Pepperdine University, USA
}

\begin{abstract}
The secondary market for video game purchases is a multi-billion dollar industry that some believe is unfair to video game developers. Using the Theory of Reasoned Action (TRA), we investigated user attitudes and subjective norms and their affect on a consumer's intention to buy new video games. While TRA has been used to study purchase intentions of material goods and digital goods, our study extends this work to investigate video games, which have both a physical and digital component. Based on a survey of 118 undergraduate students, two of the hypothesized relationships are significant predictors of intention to purchase: previous experience in the primary market and access to the secondary market. The results of this study highlight the applicability of TRA to the video game market, suggest marketing strategies for video game developers, and caution against criminalizing the resale of video games.
\end{abstract}

Keywords: Theory of Reasoned Action; Video Game Purchase Intentions; Secondary Market For Video Games

\section{INTRODUCTION}

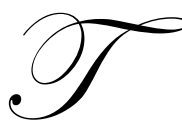

he video game industry consists of multiple elements that are associated with interactive entertainment. The video game market in the United States reported \$11 billion dollars in new game sales in 2008 (Entertainment Software Association, 2009). Indeed, a chief economist at the Los Angeles County Economic Development Corporation has said, "The video game sector is no longer an interesting little industry - it's serious money" (Entertainment Software Association, 2009 p. 11). A recent study conducted by the Entertainment Software Association found that $68 \%$ of American households play computer or video games, and that $43 \%$ of Americans purchased or planned to purchase one or more games in 2009 (Entertainment Software Association, 2009).

The secondary market of this industry involves the resale and trade of video games. This market for used video games has also grown to become a multi-billion dollar industry (Morris, 2010). The current economic downturn has prompted firms such as Amazon and Toys R' Us to capture part of this market share (Fletcher, 2009). Game developers, however, are also caught in a tight economy and only realize profits from the sale of new video games.

Some consider the resale market of used video games unfair to video game developers and are even calling it piracy (Lowell, 2010). Retailers often recognize much larger gross margins on the sale of used games compared to new games. For example, GameStop reported a gross margin of 46.8\% on used games in 2009 (University of Oregon Investment Group, 2010) and a gross margin of only $21 \%$ on new games in 2009 (University of Oregon Investment Group, 2010). Some retailers credit the video game secondary market with keeping them in business (Kennedy, 2007). In contrast, video game developers do not receive any of the proceeds from secondary market sales (Paprocki, 2011) and believe that this secondary market hurts their bottom line.

Others, however, believe that a legal secondary market is beneficial to consumers and contend that the possibility of future sales may actually lead to an increase in new game sales (Chalk, 2008). For example, owners can trade-in existing games and game systems, thereby decreasing the consumer's cost of entering a new gaming 
platform environment (Chalk, 2008). In addition, when consumers choose to purchase a new game, they generally assume some degree of risk. Having the option to resell at a later date effectively minimizes their risk (and cost) by allowing them to artificially "rent" the game on a longer-term basis. Finally, a rational consumer believes at the time of purchase that the utility the game will provide exceeds its monetary cost (McBurney et al., 2003). The utility each consumer receives from a particular game will likely decrease over time, but a secondary market still provides consumers with a residual monetary value for each game, and is therefore still good for consumers.

The effect of a consumer's ability (or inability) to sell used video games on purchase behavior has not been studied. That is, does the future possibility of selling a used video game affect a consumer's intention to buy a new video game? Using the Theory of Reasoned Action (TRA), we investigate predictors of video game purchase intentions. TRA states that specific behaviors can be predicted by behavioral intentions; these behavioral intentions are in turn influenced by attitudes toward the behavior and perceived subjective norms (Ajzen and Fishbein, 1980). Using TRA and prior studies to guide our research, we identified relevant factors that may be predictive of intention to purchase, including: previous experience, access to the secondary market, and game reputation in addition to measures of subjective norm.

This project has strong implications for both industry and research. While TRA has been shown to have strong predictive power with various material or digital consumer goods (e.g., Sheppard et al., 1988; Ryan, 1982; Ang et al., 2001), it has not yet been tested with consumer goods that include both a physical and digital component, such as video games. This study presents a unique opportunity to test the applicability of TRA in another context. Beyond academia, the potential consequences of making the resale of video games a crime are important to retailers, game developers and lawmakers.

The remainder of the paper is organized as follows. Section 2 provides further background and a review of the relevant literature, followed by an overview of TRA. Section 3 develops the research hypotheses, followed by a discussion of the methodology in Section 4. Data analysis and results are presented in Section 5, followed by a discussion of the results in Section 6. Section 7 concludes with limitations and research implications.

\section{BACKGROUND}

\subsection{Secondary Markets}

The importance of secondary markets has been well established in many consumer goods markets. For example, consumer behavior may change if individuals were not allowed to resell goods such as automobiles and homes. Indeed, the resale value of these items is often considered to be a high priority by consumers when making a purchasing decision (e.g., Lui, 1995; Byun, 2001). Although the cost of a video game, or even a video game system, is much lower than the cost of a house or an automobile, yard sales and the proliferation of online secondary markets such as eBay and Craigslist suggest that consumers value resale opportunities for many categories of consumer goods. Furthermore, studies have shown that the removal of a secondary market can impact consumer purchase behaviors (e.g., Chiu 2002). Clearly, secondary markets have been shown to influence consumer behavior, and we argue that this influence is relevant to the video game market as well.

However, there are still mixed opinions about the impact of secondary markets on primary markets. Economic theory suggests there are two possible consequences with regard to durable goods (Benjamin and Kormendi, 1974). First, new and used goods would be considered substitutes, which may decrease market power for makers of new goods, but may not affect the price of goods. The second possible consequence states that the price of a good is inclusive of its future resale value; in this case, any elimination of a secondary market would reduce this future resale value, and therefore reduce the sale price of the good and negatively impact manufacturers. In his investigation of primary and secondary textbook markets, Miller (1974) found that consumers did not perceive used books to be equal substitutes for new books, and that consumers considered this before making a purchase. His results suggested that eliminating the secondary market would have little effect on the sales of new textbooks. These inconsistent findings suggest further research into the impact of secondary markets as a whole is warranted. 


\subsection{The Video Game Market}

Although the video game industry has been a significant force in American media for the past two decades, most early research focused on violence, aggression, and gender roles that exist within the games (Williams, 2002). Other studies have investigated the video game market from a historical lens (e.g., Gallagher and Park, 2002). More recent studies have investigated the video game industry and market. Williams (2002) presented an analysis of the video game industry and concluded that it represented a mature market with product diversity. In this mature market, the major platform developers (such as Nintendo and PlayStation) sell consoles at a loss to "hook" consumers to their technology, with a core strategy of recouping costs through the sale of video games. This strategy explains the developers' strong aversion to the video game secondary market. However, these investigations have studied the market from the perspective of the firm (e.g., Shankar and Bayus, 2003). Our study investigates the video game market from the perspective of the consumer, using the Theory of Reasoned Action to guide our inquiry.

\subsection{Theory of Reasoned Action}

TRA proposes that people are rational actors, whose behavior is influenced by a corresponding behavioral intention, and that this behavioral intention, in turn, is influenced by their attitudes toward that behavior and subjective norm (Ajzen and Fishbein, 1980). Behavioral intention is a measure of the strength of one's intention to perform a behavior; attitudes toward a behavior are a reflection of one's beliefs about the importance and consequences of the behavior; and subjective norm represents an individual's social and environmental pressures related to the behavior. These constructs are presented in detail in Ajzen et al.(2005).

TRA has been shown to have strong predictive power for user intentions to purchase when studying material goods (e.g., dog food (Miniard and Cohen, 1981), toothpaste (Ryan, 1982), and mineral water (Knox and Chernatony 1989)). It has also been used in studies regarding the piracy of digital goods (e.g., pirated music (Ang et al., 2001; d'Astous et al., 2005) and the purchase of pirated software (Peace et al., 2003)). However, TRA has not yet been used to investigate purchase behaviors of legal goods that have both a physical and digital component. Furthermore, our research tests TRA in this new context while extending the model to include user attitudes about the secondary market. The inclusion of secondary market in our study represents an important extension to TRA by including not only attitudes about the consumer good itself, but also attitudes regarding a future market of that consumer good.

\section{HYPOTHESIS DEVELOPMENT}

As outlined above, the TRA states that behaviors are predicted by behavioral intentions, which are in turn influenced by one's attitudes and subjective norm (Ajzen and Fishbein, 1980). In studying one's intention to purchase a new video game, we identified three attitudes: previous experience, accessibility of the secondary market, and game reputation. These, in addition to subjective norm, are described below.

Several studies have shown previous experience with a given behavior has a significant influence on one's intention to engage in that behavior in the future (Eagly and Chaiken, 1993). Phrased as an attitude about the importance or consequences of video game purchases, buying a video game in the past is a reflection of one's belief that purchasing a video game is important or acceptable. Kwong et al. (2003) found that people who had purchased pirated CDs in the past had greater intentions to buy pirated CDs in the future. Tom et al. (1998) found that U.S. buyers who had purchased counterfeit goods in the past had more positive attitudes about counterfeiting. Finally, d'Astous et al. (2005) found that previous experience with online music piracy had a strong positive influence on one's intention to do it again in the future. This suggests that purchasing a video game in the past may have an impact on one's intention to purchase a video game again. Stated formally:

H1. There is a positive relationship between purchasing video games in the past and one's intention to purchase a new video game. 
As an influential attitude, one's perceptions of the accessibility of a secondary market reflects beliefs about possible future consequences of video game purchases; namely, if resale will be easy. Indeed, perceived accessibility of a secondary market may act as a signal of future ease of resale. This is likely to influence purchase behavior for two reasons. First, the option to resell in the future minimizes the risk of making a poor purchase decision by allowing one to artificially "rent" the video game. Second, industry analysts suggest that video game owners may view their games as goods that can be used toward future barters or purchases (Chalk, 2008). Indeed, future resale value has been shown to be important in consumers' purchase decisions in other goods (e.g., Lui, 1995; Byun, 2001). We argue that the perceived accessibility of a secondary market signals to customers that their purchases are less risky and may constitute an investment into future gaming. As such:

H2. There is a positive relationship between one's perceived access to the video game secondary market and one's intention to purchase a new video game.

The brand of a consumer good has been shown to affect purchase decisions (e.g., Chu et al., 2005). Previous work has also found that the reputation of a particular band or singer was an important influence to one's intentions to purchase pirated CDs (Chiou et al., 2005). In fact, research has shown that the purchase of a good is a signal of loyalty to a product or its creator (Raviv et al., 1996). As such, the reputation of a particular video game or video game developer reflects the importance of purchase. This gives us hypothesis three:

H3. There is a positive relationship between a video game's reputation and one's intention to purchase a new video game.

The final influence on intentions suggested by TRA is subjective norm. Fishbein and Ajzen define it as "the person's perception that most people who are important to him think that he should or should not perform the behavior in question" (1975, p. 302), and subjective norm has been shown to influence user behavior in many studies (e.g., d'Astous et al., 2005; Bearden et al., 1989). Indeed, online forums suggest that when people talk about video games, they often mention playing with friends. With the prevalence of social networking, we expand the idea of subjective norm to include both friends (in a traditional conceptualization of subjective norm) and expanded social circles, such as facebook and word of mouth. Recent research suggests that expanded social circles, such as friends of friends and similar indirect relationships as seen in facebook often provide product information that is used by consumers (e.g., Cheong and Morrison, 2008). Stated formally:

H4. There is a positive relationship between one's perception that important people and friends in their immediate social circles think that they should participate in the video game market and one's intention to purchase a new video game.

H5. There is a positive relationship between one's perception that important people and friends in their extended social circles think they should participate in the video game market and one's intention to purchase a new video game.

\section{METHOD}

Because we were interested in collecting user perceptions, a survey methodology was used. Paper-based surveys were administered to undergraduate business students at a university in the western United States. Survey completion was voluntary and standard incentives (e.g., iPod Nano, gift cards) were offered. Of the 118 survey respondents, 74 were male $(62.7 \%), 39$ were female $(33.1 \%)$, and five did not disclose their gender (4.2\%). The average age was 20.5, ranging from 18 to 25 years, which is within our target demographic (Entertainment Software Association, 2009).

To avoid problems with confounding results (e.g., computer games that can be downloaded onto a computer, Facebook games, etc.), this research focuses on video games, also referred to as console games. These games differ from computer games in that they have a distinct physical and digital component, both of which are necessary for game play, and which provide the game owner with a tangible good that can be sold. Examples of top video games as measured by sales units include Wii Fit, Mario Kart, and Grand Theft Auto (Entertainment Software 
Association, 2009). In contrast, computer games may involve a physical component (like a CD) that can be installed on a computer or may just be downloaded or accessed online. Examples of top computer games as measured by sales units include World of Warcraft, The Sims, and Fallout (Entertainment Software Association 2009).

Following Dillman's Total Design Method (Dillman, 1978), we adapted previous questions when possible and developed new questions based on theory, refining the new items using a card sorting task and expert review. Items measuring previous experience were adapted from Kwong et al. (2003) and augmented with additional items. Items measuring access to a secondary market were adapted from Moores and Dhaliwal (2004). Items measuring reputation were adapted from Chiou et al. (2005). Items measuring subjective norm were adapted from Bearden et al. (1989). Items measuring intention to purchase were adapted from Chiou et al. (2005). Finally, we included two control variables previously shown to influence purchase decisions: gender and income (e.g., Ang et al., 2001). Before implementing the survey, the instrument was reviewed by fellow researchers and video game players.

\section{RESULTS}

\subsection{Measurement Model}

To begin, the validity and reliability of each construct in the model was tested. A factor analysis was conducted using principal component extraction with varimax rotation. Any items not loading at least 0.6 on its respective construct was dropped. All items load more than 0.6 on their respective constructs ${ }^{1}$, providing initial evidence of convergent validity (Chin, 1998; Fornell and Larcker, 1981). Average variance extracted (AVE) was also used to assess the convergent validity of our constructs. AVE measures range from 0 to 1 and adequate validity is found in AVE measures above 0.50 (Fornell and Larcker, 1981); all AVE measures are well above 0.50 as shown in Table 1.

To establish satisfactory discriminant validity, the square root of AVE for each construct should be greater than the correlations with other constructs (Chin, 1998). In all cases, the square root of AVE for each construct (shown in bold on the diagonal in Table 1) is larger than the correlation of that construct with all other constructs in the model. Finally, the scale reliability of our constructs was assessed with Cronbach's alpha. Cronbach's alpha measures for all scales exceeded the 0.7 value recommended by Nunnally (1978). Therefore, the validity and reliability of our measures were established.

Table 1. Cronbach's alpha, AVE, and construct correlations, with square root of AVE on diagonal

\begin{tabular}{|l|c|c|c|c|c|c|c|c|}
\hline \multicolumn{2}{|c|}{} & \multicolumn{6}{|c|}{ Correlations } \\
\hline & Cronbach's alpha & AVE & $\begin{array}{c}\text { Prev } \\
\text { Exp }\end{array}$ & $\begin{array}{c}\text { Access } \\
\text { Sec }\end{array}$ & Rep & $\begin{array}{c}\text { SN } \\
\text { Friends }\end{array}$ & $\begin{array}{c}\text { SN } \\
\text { Ext }\end{array}$ & $\begin{array}{c}\text { Inten- } \\
\text { tion }\end{array}$ \\
\hline Previous Experience & 0.900 & 0.678 & $\mathbf{0 . 8 2 3}$ & & & & & \\
\hline Access to Secondary Market & 0.832 & 0.671 & -0.046 & $\mathbf{0 . 8 1 9}$ & & & & \\
\hline Reputation & 0.863 & 0.803 & 0.093 & -0.069 & $\mathbf{0 . 8 9 6}$ & & & \\
\hline Subjective norm: friends & 0.933 & 0.681 & 0.080 & 0.066 & 0.080 & $\mathbf{0 . 8 2 5}$ & & \\
\hline Subjective norm: extended & 0.916 & 0.701 & 0.071 & $0.218^{*}$ & -0.013 & $0.216^{*}$ & $\mathbf{0 . 8 3 7}$ & \\
\hline Intention to Purchase & 0.873 & 0.726 & $0.472^{* *}$ & $0.236^{*}$ & 0.112 & 0.147 & $0.202^{*}$ & $\mathbf{0 . 8 5 2}$ \\
\hline
\end{tabular}

** Correlation is significant at the 0.01 level (2-tailed).

* Correlation is significant at the 0.05 level (2-tailed).

\section{2. Analysis and Results}

To test our hypotheses, a two-step regression analysis was performed. First, the control variables were introduced, and then the independent variables were added. All decision variables were normally distributed. Results are reported in Table 2.

\footnotetext{
${ }^{1}$ Survey items and their factor loadings can be requested from the corresponding author. 
The hypothesized model (Model 2) explains 39.1\% of the variance in one's intention to purchase a video game. The corresponding model including only the control variables (Model 1) is significant, with 6.7\% of the variance being explained by gender.

The multiple regression results indicate that one's intention to purchase a video game was positively influenced by previous experience and access to the secondary market, thus supporting $\mathrm{H} 1$ and $\mathrm{H} 2$, respectively. However, the results do not support the expected positive effect of game reputation (H3), subjective norm of friends (H5), or subjective norm of one's extended social circle (H6). None of the control variables are significant in the regression including the hypothesized independent variables, indicating that there is no significant difference between men and women in video game purchase intentions when considering other factors.

Table 2. Regression Results

\begin{tabular}{|l|c|c|}
\hline \multicolumn{1}{|c|}{ Table 2. Regression Results } \\
\hline \multicolumn{1}{|c|}{ Independent Variables } & Model 1 & Model 2 \\
\hline Gender & $0.298 * *$ & -0.130 \\
\hline Income & -0.031 & 0.084 \\
\hline H1: Previous Experience & & 0.520 \\
\hline H2: Access to Secondary Market & & 0.240 \\
\hline H3: Reputation & & 0.110 \\
\hline H4: Subjective norm: Friends & & 0.112 \\
\hline H5: Subjective norm: Extended & & \\
\hline & & 0.104 \\
\hline $\mathrm{R}^{2}$ & 0.088 & 0.440 \\
\hline Adj $\mathrm{R}^{2}$ & 0.067 & 0.391 \\
\hline Model F & 4.189 & 9.148 \\
\hline $\mathrm{R}^{2}$ change & & 0.352 \\
\hline F change & & $* * *$ \\
\hline
\end{tabular}

$* \mathrm{p} \leq 0.1, * * \mathrm{p} \leq 0.05, * * * \mathrm{p} \leq 0.001$

\section{DISCUSSION}

Previous Experience reflected a respondent's past behavior with regard to playing and purchasing video games in both the primary and secondary markets and was a significant determinant of future behavior. This confirms prior research, which shows that previous experience has influenced intention to buy pirated CDs (Kwong et al., 2003), the intention to purchase pirated software (Tan, 2002), counterfeiting (Tom et al., 1998), music piracy on the web (d'Astous et al., 2005) and new rock music (Lacher and Mizerski, 1994). As a significant influence on one's intention to purchase a video game, this suggests the primary video game market is driven by consumers who have made prior purchases or trades. These consumers' intentions are integral to video game sellers. This may also imply that the purchasing of other goods with a digital and physical component will be influenced by consumers' previous experience.

We found that the accessibility, and not just legality, of the video game secondary market was also a significant predictor of new video game purchase. This finding represents a significant extension of TRA to include not only attitudes about the consumer good, but also attitudes about the market. For this construct, respondents' knowledge of physical and on-line places to buy, sell and trade video games was important. Furthermore, the construct also reflected the ease of participating in the secondary market. This confirms previous research seen in studies by Chiou et al. (2005), Moores and Dhaliwal (2004), and Penz and Stottinger (2005). These results suggest that video games may be similar to other consumer goods. Although our study did not address the secondary market as a dependent variable, we may assume that one's intention to purchase a video game from a secondary market will also be influenced by their access to that market.

Reputation was not significant in our analysis. This is surprising, because previous research has found reputation and brand to influence purchase behavior (e.g., Chu et al., 2005; Fombrun, 1996). Our results may be 
specific to the rapidly changing video game market. That is, consumers may be used to a continual emergence of large numbers of new game makers and games, making reputation less important.

Neither of the subjective norm constructs was found to be significant. This is also surprising, because previous studies have found subjective norm to be a significant predictor in intention to purchase counterfeits (Penz and Stottinger 2005), pirated DVDs/VCDS and software (Wang, 2005), and music piracy on the web (d'Astous et al., 2005). Furthermore, a recent MIT Sloan Business in Gaming Conference cited the importance of viral growth (Mangelsdorf, 2011) in social games.

\section{CONCLUSION}

Before we discuss the contributions of the present study, it is important to address some potential limitations. First, this study utilized a cross-sectional study, which only captures respondents' perceptions at a point in time and doesn't allow an examination of longitudinal effects. Second, our study sample was comprised of undergraduate students, but these respondents fell well within the target demographic (Entertainment Software Association, 2009), so there is no reason to believe these results are not generalizable. Finally, this study presents an initial investigation into intentions to purchase new video games. While this represents an important first step, future studies and further instrument refinement would be beneficial.

Despite these limitations, this research presents significant contributions to research and practice. First, this study demonstrates the applicability of TRA to consumer goods with both a digital and physical component, namely, video games. These findings may extend to other goods with both physical and digital components, such as mobile devices and e-readers.

Second, this study suggests that while TRA can be used to evaluate many consumer goods, additional research is necessary to better understand the video game market. An important extension of this work would involve the investigation of computer games. That is, do purchase intentions differ when the game has no physical component? Furthermore, effects of a secondary market should be investigated in the context of computer games. In this case, no real secondary market exists for many computer games because the software is merely downloaded or accessed directly from the Internet.

Third, subjective norm was not significant in this study. Future research should investigate the effects of primary and extended social influences on intentions to purchase and/or play other kinds of games, such as massive multi-player online role-playing games and social games, as a major component of game play in these games involve others; while game makers often assume purchase intentions are strongly influenced by social networks, this has not been studied.

Finally, our results support the stereotype that males are more likely to purchase video games than females when no other influences are considered (Model 1). However, this contradicts current industry analysis that counts women as nearly half of all video game players and purchasers (Entertainment Software Association 2009). Future research should extend this study to include computer game purchases as well video and computer game playing behaviors. For example, some computer games are available for free online, such as Farmville. Other video games may be purchased by only a fraction of the people who play them; examples include group games such as Guitar Hero or Wii Sports.

In addition to the research aspects listed above, our study has important implications for practice. First, this study suggests that the accessibility - and not just legality - of a secondary market is important to consumers' purchase behaviors in the primary market. Our results suggest that game developers and publishers would be wise to reassess their push to criminalize the resale of video games. For example, wary consumers may first purchase video games from the secondary market, and this low-cost exposure to video games may create gamers who later transition to purchasers from the primary market. If the secondary market is illegal or difficult to access, these consumers may never enter the video game market at all, thereby hurting future sales. 
Second, our study may inform marketing strategies that may be effective for video game makers and retailers. Our study suggests that targeting consumers who have purchased video games in the past is a good population on which to focus marketing efforts. Our results also suggest that providing accessibility to a secondary market may increase sales. Furthermore, our findings suggest that game reputation and branding are not significant predictors of purchase intentions, so advertising approaches may benefit from reexamination. Finally, results suggest that advertising through facebook and word of mouth is not effective for the video game primary market.

This study has provided a preliminary investigation into the applicability of TRA to video game purchase intentions and the impact of a secondary market on primary market purchases. Our results suggest that video game makers and retailers should improve the accessibility of the secondary market, rather than eliminate or criminalize it. Although future research is needed to support these findings, we believe that this work provides an important first step towards better understanding important factors in consumers' video game purchase intentions.

\section{AUTHOR INFORMATION}

Nicole F. Velasquez is an Assistant Professor of MIS and Accounting at Utah State University. Prior to her position at USU, Dr. Velasquez was an Assistant Professor at Pepperdine and a Post-doctoral Research Associate at the University of Arizona. She has also worked at IBM as a software engineer and performance analyst for enterprise storage. She received her Ph.D. in Management Information Systems and her Masters in Accounting from the University of Arizona. E-mail: nicolefv@ gmail.com. Corresponding author.

Hannah Newman is an accounting major and music minor at Pepperdine University. After graduation, she plans to work in public accounting with KPMG in Los Angeles. E-mail: hannah.j.newman @ pepperdine.edu

Scott Miller is an Assistant Professor of Finance at Pepperdine University. Prior to his position at Pepperdine, Dr. Miller taught for the Walton College of Business at the University of Arkansas and has worked extensively with mutual funds at Principal Financial Group in his role as a financial accountant. He received his PhD from the University of Arkansas and his MBA from Drake University. E-mail: scott.miller@pepperdine.edu

\section{REFERENCES}

1. Ajzen, I. and Fishbein, M. (1980). Understanding Attitudes and Predicting Social Behavior. Englewood Cliffs, NJ: Prentice-Hall.

2. Ajzen, I., Fishbein, M. and Zanna, M.P. (2005). The Influence of attitudes on behavior, in the handbook of attitudes, Editors Erlbaum: Mahwah, NJ.

3. Ang, S.H., Cheng, P.S., Lim, E.A.C., and Tambyah, S.K. (2001). Spot the difference: consumer responses towards counterfeits. Journal of Consumer Marketing, 18(3), 219-235.

4. Bearden, W.O., Netemeyer, R.G. and Teel, J.E. (1989). Measurement of Consumer Susceptibility of Interpersonal Influence. Journal of Consumer Research, 15(4), 473-481.

5. Benjamin, D., and Kormendi, R. (1974). The Interrelationship between markets for new and durable goods. Journal of Law and Economics, 17.

6. Byun, D. (2001). The AHP approach for selecting an automobile purchase model. Information \& Management, 38(5), 289-297.

7. Chalk, A. (2008). GameStop CEO says restricting used game sales is bad for everyone. The Escapist Magazine. Retrieved from http://www.escapistmagazine.com/news/view/87678-GameStop-CEO-SaysRestricting-Used-Game-Sales-Is-Bad-For-Everyone (accessed 5 July 2011).

8. Cheong, J., and Morrison, M. (2008). Consumers' reliance on product information and recommendations found in UGC. Journal of Interactive Advertising, 8(2) 38-49.

9. Chin, W.W. (1998). "Issues and opinion on structural equation modeling," MIS Quarterly, (22) VII-XVI.

10. Chiou, J.-S., Huang, C. and Lee, H. (2005). The Antecedents of Music Piracy Attitudes and Intentions. Journal of Business Ethics, 57(2), 161-174.

11. Chiu, R. (2002). Social equity in housing in the Hong Kong Special Administrative Region: a social sustainability perspective. Sustainable Development, 10(3), 155-162. 
12. Chu, W., Choi,, B., and Song, M.R. (2005). The role of on-line retailer brand and infomediary reputation in increasing consumer purchase intention. International Journal of Electronic Commerce, 9(3), 115-127.

13. d'Astous, A., Colbert, F., and Montpetit, D. (2005). Music piracy on the web - how effective are antipiracy arguments? Evidence from the theory of planned behavior. Journal of Consumer Policy, 28(3), 289-310.

14. Dillman, D.A. 1978. Mail and Telephone Surveys. John Wiley \& Sons, New York.

15. Eagly, A.H., and Chaiken, S. (1993). The psychology of attitudes. Orlando, FL: Harcourt Brace Jovanovich College Publishers.

16. Entertainment Software Association. (2009). Essential Facts About the Computer and Video Game Industry: 2009 Sales, Demographic and Usage Data. Retrieved online: www.theesa.com/facts/pdfs/ESA EF_2009.pdf (accessed 5 July 2011).

17. Fletcher, J.C. (2009). Amazon vs. Toys R Us vs. GameStop: Which is the best trade-in service? Joystiq.com. Retrieved from http://www.joystiq.com/2009/03/10/amazon-vs-toys-r-us-vs-gamestopwhich-is-the-best-trade-in-se/ (accessed 5 July 2011).

18. Fombrun, C. (1996). Reputation: Realizing Value from the Corporate Image. United States of America: Harvard Business School Press.

19. Fornell, C., D. Larcker. 1981. Evaluating Structural Equation Models with Unobservable Variables and Measurement Error. Journal of Marketing Research, 18(2) 39-50.

20. Gallagher, S., and Park, S.H. (2002). Innovation and competition in standard-based industries: A historical analysis of the U.S. home video game market. IEEE Transactions on Engineering Management, 49(1), 6782.

21. Kennedy, K. (2007). Used video games keep some retailers afloat. The Ledger. Retrieved from http://www.theledger.com/article/20070527/NEWS/705270333 (accessed 5 July 2011).

22. Knox, S. and Chernatony, L. (1989). The application of multiattribute modeling techniques to the mineral water market. Quarterly Review of Marketing, 14(4), 14-20.

23. Kwong, K., Yau, O.H.M., Lee, J.S.Y, Sin, L.Y.M and Tse, A.C.B. (2003). The effects of attitudinal and demographic factors on intention to buy pirated CDs: The case of Chinese consumers. Journal of Business Ethics, 47(3), 223-235.

24. Lacher, K., and Mizerski, R. (1994). An exploratory study of the responses and relationships involved in the evaluation of, and in the intention to purchase new rock music. Journal of Consumer Research, 21(2), 366-380.

25. Lowell, M. (2010). Used video games: The new software piracy. The-ghetto.org. Retrieved from http://www.the-ghetto.org/content/used-video-games-the-new-software-piracy (accessed 5 July 2011).

26. Lui, T. (1995). Coping strategies in a booming market. Housing and family wealth: Comparative international perspectives. United States of America: Taylor \& Francis.

27. Mangelsdorf, M.E. (2011, March 22). Video Games by the Numbers [MIT Sloan Management Review Blog: Improvisations]. Retrieved from http://sloanreview.mit.edu/improvisations/2011/03/22/video-gamesby-the-numbers/ (accessed 5 July 2011).

28. McBurney, P., van Eijk, R.M., Parsons, S. and Amgoud, L. (2003). A Dialogue Game Protocol for Agent Purchase Negotiations. Autonomous Agents and Multi-Agent Systems, 7, 235-273.

29. Miller, H.L. (1974). On killing off the market for used textbooks and the relationship between markets for new and secondhand goods. Journal of Political Economy, 82(3), 612-619.

30. Miniard, P.W. and Cohen, J.B. (1981). An examination of Fishbein-Ajzen behavioral intentions model's concepts and measures. Journal of Experimental Social Psychology, 17, 309-339.

31. Moores, T. and Dhaliwal, J. (2004). A Reversed Context Analysis of Software Piracy Issues in Singapore. Information \& Management 41, 1037-1042.

32. Morris, C. (2010). Target looking for piece of used video game market. CNBC.com. Retrieved from http://www.cnbc.com/id/38853378/Target_Looking_for_Piece_of_Used_Video_Game_Market (accessed 5 July 2011).

33. Nunnally, J.C. (1978). Psychometric Theory. New York: McGraw-Hill.

34. Paprocki, M. (2011). Game developer Denis Dyack speaks against used game sales. The Morton Report. Retrieved from http://www.themortonreport.com/entertainment/game-developer-denis-dyack-speaksagainst-used-game-sales/ (accessed 5 July 2011). 
35. Peace, A.G., Galletta, D.F., and Thong, J.Y. (2003). Software piracy in the workplace: A model and empirical test. Journal of Management Information Systems, 20(1), 153-177.

36. Penz, E. and Stottinger, B. (2005). Forget the "Real" Thing-Take the Copy! An Explanatory Model for the Volitional Purchase of Counterfeit Products. Advances in Consumer Research, (32), 568-575.

37. Raviv, A., Bar-Tal, D., Raviv, A., and Ben-Horin, A. (1996). Adolescent idolization of pop singers: Causes, expressions, and reliance. Journal of Youth and Adolescence, 25(5), 631-650.

38. Ryan, M.J. (1982). Behavioral intention formation: the interdependency of attitudinal and social influence variables. Journal of Consumer Research, 9(3), 263-278.

39. Shankar, V., and Bayus, V. (2003). Network effects and competition: An empirical analysis of the home video game industry. Strategic Management Journal, 24, 375-384.

40. Sheppard, B.H., Hartwick, J., and Warshaw, P.R. (1988). The Theory of Reasoned Action: A MetaAnalysis of Past Research with Recommendations for Modifications and Future Research. The Journal of Consumer Research, 15(3), 325-343.

41. Tan, B. (2002). Understanding consumer ethical decision making with respect to purchase of pirated software. Journal of Consumer Marketing, 19(2), 96-111.

42. Tom, G., Garibaldi, B., Zeng, Y., and Pilcher, J. (1998). Consumer demand for counterfeit goods. Psychology and Marketing, 15(5), 405-421.

43. University of Oregon Investment Group (2010). GameStop Corporation Company Analysis. Retrieved from Uoig.uoregon.edu

44. Wang, J. (2005). From advertising to branding: Framing Chinese consumer culture. London: RoutledgeCurzon.

45. Williams, D. (2002). Structure and competition in the U.S. home video game industry. The International Journal of Media Management, 4(1), 41-54. 